\title{
Personal, Professional and Financial Satisfaction among American Women Urologists
}

\author{
Ciara S. Marley, Lori B. Lerner, Georgia Panagopoulos, Elizabeth Kavaler \\ Department of Urology (CSM, GP, EK), Lenox Hill Hospital, New York, USA and VA Boston \\ Healthcare System (LBL), West Roxbury, USA
}

\begin{abstract}
Purpose: Although nearly half of American medical school classes are comprised of women, less than 5\% of female medical students enter the surgical subspecialties compared to nearly $20 \%$ of male students. Many women are concerned that a career in a surgical field will limit their personal choices. In an effort to evaluate if urology is conducive to a satisfying lifestyle, we surveyed all 365 board certified women urologists in the United States in 2007 to find out how satisfied they are with their choice of urology.

Materials and Methods: A 114 item anonymous survey was mailed to all 365 American Board Certified female urologists in 2007. Results were analyzed.

Results: Of the 244 women (69\%) who responded, $86.8 \%$ (211) reported being satisfied with their decision to enter urology. Given the choice to repeat the decision, $81 \%$ (198) said that they would remain in medicine and $91.4 \%$ (222) would choose a surgical subspecialty again. The majority of respondents who stated they would choose a career outside of medicine also stated their family life had been significantly compromised by their career. Those who did not think their family life was compromised reported they would remain in medicine. There was a positive correlation between the level of satisfaction with the work itself and with income level $(\mathrm{p}=0.006)$.

Conclusions: Despite the small number of women who choose a career in urology, the number of satisfied women indicates urology is a career conducive to having a balanced and fulfilling life; professionally, personally and financially.
\end{abstract}

Key words: urology; urologists; women; clinical practice

Int Braz J Urol. 2011; 37: 187-94

\section{INTRODUCTION}

The surgical subspecialties continue to remain desirable and competitive residencies among American medical students of both genders (1). Over the last 3 decades, female medical students have entered the surgical subspecialties in escalating numbers. However, women are not entering these highly competitive professions at nearly the rate of their male counterparts. Despite the fact that half of American medical school classes are comprised of women, less than $5 \%$ enter the surgical subspecialties (1).

Women still only constitute $13 \%$ of all surgeons in total (2). There has been a recent surge of interest across surgical fields concerning the level of satisfaction among women surgeons, with an effort to understand the implications of an evolving field for females considering a surgical career (2). Having women adequately represented among the surgical subspecialties offers a more diverse workforce, reflecting the society in which we live and serve. 
Like most surgical fields, urology remains a male-dominated profession. In urology the number of women applying for residency positions has increased over recent years, yet the number of male applicants far outweighs the number of female applicants, $(271$ male applicants vs. 77 female applicants $-28 \%$ - in 2007 match). Data for 2007 show that women fill approximately $21 \%$ of the urology residency positions (211 out of 985 total residents). The reasons for this gender discrepancy are not fully understood. In one recent study, $84 \%$ of women medical students cited lifestyle during residency as influencing their career decision. Sixty-three percent of women selected other factors, including practice lifestyle and length of training (3). In fact, lifestyle considerations were the only significant factor influencing the decision about surgical training affecting women more than men (4).

In an effort to evaluate if the field of urology is conducive to a fulfilling lifestyle for women, we surveyed all 365 board certified women urologists in the United States to assess how satisfied they are with their choice of urology professionally, personally and financially.

Table 1 - Survey satisfaction questions.

So far as you and your family are concerned, would you say that you are satisfied with your present financial situation?

On the whole, how satisfied are you with the work you do?

How much satisfaction do you derive from your family life?

Overall, how would you describe your marriage?

Overall, how would you describe your current life satisfaction?

Are you satisfied with the way you manage your time between career and family/personal responsibilities?

Do you feel that your personal life and family responsibilities have compromised your career?

Do you feel that your career has compromised your family and personal life?

If you could do it all over again, would you choose a non-surgical specialty?

If you could do it all over again, would you choose a career outside of medicine?

\section{MATERIALS AND METHODS}

We obtained a list of all 365 American board certified women urologists from American Board of Urology and the Society of Women in Urology. The 114-item survey was mailed to all women in May and July 2007. Given the personal nature of the survey, including questions on institutional policies, no respondent identifier or tracking mechanism was used. A pre-addressed stamped return envelope was included. For tracking purposes an included pre-addressed response postcard was to be returned separately. Approval was granted from the Institutional Review Board of the VA Boston Healthcare System. The survey methods have been described in further detail in previous publications $(5,6)$.

Demographic data concerning marital status, family life, and financial compensation were obtained, as well as detailed information regarding training and overall satisfaction. The data were then entered into an online software program, Zoomerang (www. zoomerang.com), for further analysis.

Descriptive statistics were used to characterize demographic data and overall responses to the survey. Percentages reflect the total responses for each individual question as not all respondents answered every question. Relationships amongst categorical variables were examined with the Fisher's exact test. We developed a logistic regression model to predict career satisfaction utilizing the following six variables as predictors: age; marital status; number of years in training; fellowship training; the number of hours worked per week; and income. A p $<0.05$ was considered a priori to indicate statistical significance. Statistical analyses were performed with SPSS version 16.0.2 (SPSS, Chicago, IL).

We utilized responses to satisfaction questions (Table-1) as well as questions regarding the degree to which the respondents' careers compromised their family and personal lives and vice versa. Selection choices for satisfaction questions included: very satisfied; moderately satisfied; moderately dissatisfied; very dissatisfied. Statistical evaluation for satisfaction included the very and moderately satisfied groups. Dissatisfaction included both the very and moderately dissatisfied groups, unless otherwise indicated. We also explored respondents' willingness to choose 
urology again if given the opportunity to alter their career decisions.

\section{RESULTS}

Of the 365 women on our mailing list, addresses were available for 354 . Two mailings culminated in a $69 \%$ response rate $(n=243)$. The average respondent age was 43 years of age (range 31-77 years). The majority of the respondents were married $(\mathrm{n}=197,81 \%)$, with most being in their first marriage $(\mathrm{n}=181,74 \%)$. Divorce and separation rates combined were $8 \%(n=20)$ among respondents. The survey identified 163 women (67.4\%) who delivered a total of 331 biological children. Six percent $(n=$ 15) of respondents were single parents at the time of survey completion. Years of training, practice environment, academic affiliation and hours worked are listed in Table-2. Satisfaction with life, salary, time management, and marriage are listed in Table-3.

The survey revealed that the number of years in training, the numbers of hours currently spent working, and private versus academic practice had no bearing on satisfaction rates. In addition, the logistic regression model did not identify any predictors of career satisfaction $(p>0.25)$. Satisfaction appears to be independent of the number of years spent training $(p=0.30)$ and independent of the type of practice entered once training is complete $(p=0.529)$. The number of hours spent working, both in and out of the operating room, does not appear to influence career satisfaction level $(\mathrm{p}=0.569)$.

There was a positive correlation between the number of hours worked and financial compensation. The highest earners reported working 41-60 hours per week. The hardest workers (and not necessarily the highest earners) worked more than 80 hours per week $[4 \%(n=9)]$. There was a positive correlation between financial compensation and the level of reported satisfaction $p=0.006$, however, it was not true that dissatisfied women earned less.

Three percent $(n=7)$ of respondents indicated that their personal life and family responsibilities have compromised their careers to a great extent. Eleven percent $(n=26)$ of respondents indicated that their career had greatly compromised their family and per-
Table 2 - Survey responses.

\begin{tabular}{|c|c|c|}
\hline & $\%$ & $\mathbf{N}$ \\
\hline First choice of medical school & 72 & 173 \\
\hline First choice of internship & 63 & 151 \\
\hline First choice of residency & 64 & 153 \\
\hline Five year program & 29 & 70 \\
\hline Six year program & 64 & 155 \\
\hline Fellowship training & 42 & 100 \\
\hline Active in clinical practice & 88 & 175 \\
\hline \multicolumn{3}{|l|}{ Work week } \\
\hline 5 days/week & 69 & \\
\hline 4 days/week & 20 & \\
\hline \multicolumn{3}{|l|}{ Work hours per week } \\
\hline $21-40$ & 12 & 29 \\
\hline $41-60$ & 59 & 139 \\
\hline $61-80$ & 23 & 53 \\
\hline \multicolumn{3}{|l|}{ Hours in OR per week } \\
\hline $0-12$ & 55 & 128 \\
\hline $13-24$ & 40 & 93 \\
\hline Hold an academic appointment & 42 & 92 \\
\hline Full time academic & 20 & 44 \\
\hline Part time academic & 22 & 48 \\
\hline Professor & 5 & 9 \\
\hline Associate Professor & 11 & 19 \\
\hline Achieved tenure & 5 & 9 \\
\hline On tenured track & 7 & 14 \\
\hline Private practice & 83 & 200 \\
\hline Publications in peer reviewed journals & 77 & 182 \\
\hline \multicolumn{3}{|l|}{ Salary per year (in thousands) } \\
\hline$\$ 0-200$ & 33 & 81 \\
\hline$\$ 200-350$ & 51 & 123 \\
\hline$\$ 350$ or more & 16 & 39 \\
\hline
\end{tabular}

$O R=$ operating room.

sonal lives. Ninety percent (19/21) of the moderately (20) to very (1) dissatisfied urologists reported a moderate to great degree of compromise of their personal life due to their career. A total of $63 \%(137 / 216)$ of the very to moderately satisfied urologists reported a moderate to great level of compromise of their personal life due to their career $(\mathrm{p}=0.024)$. In spite of these realities, $81 \%(\mathrm{n}=198)$ would remain in medicine, and $91.4 \%(\mathrm{n}=222)$ would choose a surgical 
Table 3 - Results of satisfaction.

\begin{tabular}{lrr}
\hline Satisfaction with Salary & 89 & 212 \\
$\quad$ Very or moderately satisfied & & \\
$\begin{array}{l}\text { Satisfaction with Life } \\
\quad \text { Very or moderately satisfied }\end{array}$ & 95 & 227 \\
$\begin{array}{l}\text { Satisfaction with time management be- } \\
\text { tween career and family/personal }\end{array}$ & & \\
$\begin{array}{l}\text { responsibilities } \\
\quad \text { Very or moderately satisfied }\end{array}$ & 73 & 175 \\
$\quad$ Very or moderately dissatisfied & 26 & 64 \\
$\begin{array}{l}\text { Marriage satisfaction } \\
\quad \text { Very happy }\end{array}$ & 57 & 137 \\
$\quad$ Moderately happy & 26 & 62 \\
\hline
\end{tabular}

subspecialty again if given the choice. Eighty-seven percent $(n=211)$ of respondents indicated that they were happy with their decision to enter urology. As expected, there was a positive correlation between those women who felt their family life was compromised by their career and those that would choose a career outside of medicine if they had the choice to do it again $(\mathrm{p}=0.002)$.

Female urologists who worked more hours achieved greater financial compensation, $(p=0.005)$ and those that are compensated well report a higher level of career satisfaction, $(p=0.006)$. When asked if their spouse/partner expected his/her career advancement to take priority over her own, $82 \%(\mathrm{n}=176)$ answered no, 13\% $(\mathrm{n}=27)$ answered yes and $6 \%(\mathrm{n}$ $=12)$ were uncertain. Fifty-seven percent $(n=128)$ of respondents stated they shared the household responsibilities equally with their partner. In our survey,

Table 4-Comparison of specialty groups.

\begin{tabular}{lcc}
\hline Specialty & $\begin{array}{c}\text { Would Choose } \\
\text { Surgical Field } \\
\text { Again }\end{array}$ & $\begin{array}{c}\text { Family / Life } \\
\text { Compromise } \\
\text { to any Degree }\end{array}$ \\
\hline Urology & $91.4 \%$ & $30 \%$ \\
General surgery & $82.5 \%$ & $58.1 \%$ \\
Gynecology & $62.1 \%$ & $59.7 \%$ \\
Otolaryngology (9) & $91 \%$ & $30.6 \%$ \\
Ophthalmology (8) & $79 \%$ & $25.2 \%$ \\
\hline
\end{tabular}

$76 \%(n=181)$ of respondents decided on their career path during medical school.

\section{COMMENTS}

There has been a growing interest in the assessment of female surgeon's self-perceived quality of life. In 1990, female surgeons in Canada were surveyed in an effort to evaluate their ability to combine their careers with their personal and family lives (7). Our study is the first to specifically target American women urologists in assessing satisfaction with career choice - professionally, personally, and financially. Overall satisfaction in this study group was very high.

In a recent publication by Troppmann et al. (2), 3507 general surgeons were surveyed regarding career and lifestyle choices. Twenty-three percent of the respondents were women. Both genders stated they would choose their profession again (women $82.5 \%$ and men $77.5 \%$ ). Overall, $83.5 \%$ of women would recommend surgery to other women $(\mathrm{p}<$ 0.001). Not surprisingly, women were more strongly in favor of part-time work opportunities for surgeons, perhaps due to the additional parenting responsibilities of women surveyed. The researchers found a growing interest by both genders for child care facilities at work, highlighting one of the many changes in the evolving surgical workplace. The results of their study suggest that maximizing recruitment and retention of women surgeons will include giving serious consideration to alternative work schedules and optimization of maternity leave and childcare opportunities.

Two studies utilizing a survey, one from which ours was adapted, revealed that career satisfaction is greater among women urologists than that seen in women specializing in other surgical fields, including ophthalmology and otolaryngology (Table-4) $(8,9)$. In one study, $75 \%$ of female ophthalmologists reported they would again choose a career in medicine if given the choice and $79 \%$ reported they would choose a surgical specialty, compared to $81 \%$ and $91.4 \%$ of our cohort. When asked if they felt that their career had compromised their family or personal lives, surgeons in the various specialties had significantly different responses. Only $40.3 \%$ of gynecologists and $41.9 \%$ 
of general surgeons reported that their career choice resulted in "some, a little, or no compromise" of their family and/or personal lives.

A study of otorhinolaryngologists revealed results that were very similar to ours (9). Only $30.6 \%$ of women otorhinolaryngologists reported that their career compromised their family or personal life to a "great deal" or a "very great deal", which is similar to the $30 \%$ found in our cohort. Also mirroring our results, $83 \%$ of women in otolaryngology would remain in medicine and $91 \%$ would choose a surgical subspecialty again (9).

In contrast to the high rates of professional satisfaction among female surgical sub specialists, primary care physicians report a growing level of dissatisfaction. A 2002 study by Landon et al. compared two satisfaction surveys among primary care physicians in 1996 and 1999. In 1996, 19.8\% of physicians were somewhat or very dissatisfied with their current practice situations versus $33.4 \%$ in 1999 , an increase of more than $50 \%(\mathrm{p}<0.001)(10)$. A more recent survey from 2008 found that only $70 \%$ of family physicians said that they "agree/strongly agree" that they would choose to practice family medicine if given the opportunity to choose again. This represents a 4\% decline compared to data from 2001 and a $9 \%$ decline compared to 1995 (11). Although this survey was not a random sampling of primary care physicians, a surprising $73 \%$ of respondents answered that they were sorry they went into primary care (11).

In a recent 2008 study by Clem et al., 2502 women emergency medicine physicians were surveyed regarding their degree of career satisfaction. Only $35.5 \%$ reported being very satisfied, $44 \%$ were satisfied, $11.1 \%$ were neutral, and $9.4 \%$ were not/very unsatisfied (12). Similarly, in a 2001 survey of 5704 general pediatricians, subspecialty pediatricians, general internists, internal medicine subspecialists, and family physicians, only $44 \%$ combined would encourage their children to pursue a career in medicine (13).

Competition for placement in urology is among the highest for all residencies. There are 112 non-military accredited urology programs in the United States. In 2008, there were 247 positions in 110 non-military accredited urology resident programs with 246 vacancies matched. Four hundred and four applicants submitted preference lists resulting in 158 unmatched applicants. Of senior medical student applicants, 70 percent were matched (4). Despite the growing number of competitive women candidates applying for positions, it does not appear that they are choosing surgical fields $(4,13)$. Lifestyle considerations appear to drive the specialty choice of female medical students (6).

If lifestyle considerations are the deterrent for many female (or male) medical students, then results such as ours refute the misconception that all surgical fields affect lifestyle. Most respondents were moderately to highly satisfied with their career and personal lives and did not feel that their personal and/or family lives were compromised. One of the explanations for this high rate of satisfaction is that the type of woman who is drawn to the demands of a surgical lifestyle has a different idea of quality of life versus a woman drawn to a primary care field. Some consideration must be given to the difference in personalities between women and their choice of medical field.

Like all survey - based studies, our analysis has limitations. First, the survey is not validated, however it has been used by three other specialties resulting in multiple publications, $(8,9)$. Secondly, the study is retrospective and respondents were asked to remember important factors from several years ago, thus there is likely some degree of recall bias. A prospectively administered survey would address this weakness. It is also possible that the responders represent a more satisfied group than the 31\% of non-responders, therefore revealing the role of self-selection of participants (the volunteer effect). In addition, respondents may have felt compelled to provide professionally desirable responses. A surgical career requires a significant time and financial commitment. Having made these sacrifices, physicians may not freely admit to negative feelings about their career choice.

It would have been interesting to compare responses of women urologists to their male counterparts and this is another limitation of the study. This would have resulted in stronger conclusions and was given great consideration and investigation by the authors. However, it proved to be logistically difficult to identify a database capable of selecting an 
appropriate male group (age and year of residency completion) and labor intensive. It is the hopes of the authors that publication of the current study will promote the importance of a future study that includes both men and women.

The strength of our study was the high response rate $(69 \%)$. Research on survey responses by physicians report rates of $54 \%$, which is lower than ours (13). Additionally, we had a national sample of board certified women urologists, thus providing a representative selection.

\section{CONCLUSIONS}

Despite the small number of women who choose a career in urology, our study reveals that urology can provide a fulfilling career, a satisfying personal life, and sufficient financial rewards to the women who choose this subspecialty. While many female medical students may be concerned that a career in a surgical field will limit their personal choices, our study refutes this. Competitive female medical students who are interested in surgical careers should be educated about the growing opportunities in urology and the high level of satisfaction personally, professionally, and financially among women in this field.

\section{CONFLICT OF INTEREST}

None declared.

\section{REFERENCES}

1. AAMC GME Track (2007 data); AMA (1997 data). AAMC Data Warehouse. available at: http://www.aamc. org/members/gwims/statistics/stats08/table02.pdf

2. Troppmann KM, Palis BE, Goodnight JE Jr, Ho HS, Troppmann C: Women surgeons in the new millennium. Arch Surg. 2009; 144: 635-42.

3. Wendel TM, Godellas CV, Prinz RA: Are there gender differences in choosing a surgical career? Surgery. 2003; 134: 591-6; discussion 596-8.

4. McCord JH, McDonald R, Leverson G, Mahvi DM, Rikkers LF, Chen HC, et al.: Motivation to pursue surgical subspecialty training: is there a gender difference? J Am Coll Surg. 2007; 205: 698-703.
5. Lerner LB, Stolzmann KL, Gulla VD: Birth trends and pregnancy complications among women urologists. J Am Coll Surg. 2009; 208: 293-7.

6. Lerner LB, Baltrushes RJ, Stolzmann KL, Garshick E: Satisfaction of women urologists with maternity leave and childbirth timing. J Urol. 2010; 183: 282-6.

7. Mizgala CL, Mackinnon SE, Walters BC, Ferris LE, McNeill IY, Knighton T: Women surgeons. Results of the Canadian Population Study. Ann Surg. 1993; 218: 37-46.

8. Mackinnon SE, Mizgala CL, McNeill IY, Walters BC, Ferris LE: Women surgeons: career and lifestyle comparisons among surgical subspecialties. Plast Reconstr Surg. 1995; 95: 321-9.

9. Grandis JR, Gooding WE, Zamboni BA, Wagener MM, Drenning SD, Miller L, et al.: The gender gap in a surgical subspecialty: analysis of career and lifestyle factors. Arch Otolaryngol Head Neck Surg. 2004; 130: 695-702.

10. Landon BE, Aseltine R Jr, Shaul JA, Miller Y, Auerbach BA, Cleary PD: Evolving dissatisfaction among primary care physicians. Am J Manag Care. 2002; 8: 890-901.

11. Young R, Webb A, Lackan N, Marchand L: Family medicine residency educational characteristics and career satisfaction in recent graduates. Fam Med. 2008; 40: 484-91.

12. Clem KJ, Promes SB, Glickman SW, Shah A, Finkel MA, Pietrobon R, et al.: Factors enhancing career satisfaction among female emergency physicians. Ann Emerg Med. 2008; 51: 723-8.

13. Shugerman R, Linzer M, Nelson K, Douglas J, Williams R, Konrad R, et al.: Pediatric generalists and subspecialists: determinants of career satisfaction. Pediatrics. 2001; 108: E40.

Accepted after revision:

July 30, 2010

\section{Correspondence address:}

Dr. Ciara S. Marley

Department of Urology

Lenox Hill Hospital,

100 East 77th Street

New York, NY 10075, USA

Fax: + 1212 434-2000

E-mail: ciaramarley@hotmail.com 


\section{EDITORIAL COMMENT}

"Life, liberty and the pursuit of happiness" are cited as unalienable rights in the United States Declaration of Independence. This study by Marley and coworkers examines the "pursuit of happiness" in personal, professional and financial satisfaction in female American Board Certified Urologists. This is a comprehensive study that reports that these urologists are in general a satisfied cohort, both at work and at home. The vast majority of women would enter a surgical subspeciality, and would choose medicine as a career if given the choice again. Despite careful analysis, there were no clear predictors of satisfaction analyzed from working pattern, years of training and type of practice. There are relevant comparisons drawn between studies of women in other surgical subspecialties who have reported similar rates of satisfaction to these urologists; and specialists such as general surgery and general medicine where satisfaction with career, and medicine in general were much lower $(1,2)$.

Of note was the high response rate from the urologists surveyed (69\%) which the authors rightly note may reflect "satisfaction bias". Interestingly, this was almost exactly the same number of respondents as replied in two studies of pregnancy and maternity carried out by one of the co-authors of the same cohort of urologists $(3,4)$ It could be presumed this is a particularly well-motivated cohort of women, or are particularly sympathetic to questionnaire based research.

Fundamentally, it is difficult to separate whether the lifestyle of surgical specialties is particularly conducive to satisfaction both professionally and personally; or whether the personalities drawn to these specialities have shaped their lives around work practices. The authors have noted this, and the difficulty in asking individuals to remember and critically assess decisions in retrospect with the possibility of recall practice. The independence of satisfaction from the multiple variables assessed demonstrates what a complex and personal subject satisfaction is to analyze.

Clearly with men forming the vast majority of American Board Certified Urologists, this study should create considerable interest in repeating the analysis to examine the satisfaction rates in male urologists. As the authors rightly note, the much larger numbers, and potentially lower response rates (2) would make a follow-on study of male urologists a considerable undertaking. However, consideration of a longitudinal prospective study of recently certified male and female urologists would allow comparison between the sexes, and over the course of a career. Hopefully interest generated by this article may encourage the American Urology Association and the American Board of Urology to continue research into satisfaction and quality of life amongst its members.

In summary, Marley et al. (5) have provided a comprehensive analysis of high rates of personal and professional satisfaction among female urologists. However, bearing in mind Abraham Lincoln's quotation "most folks are about as happy as they make up their minds to be" it remains unclear if the high rates of fulfillment are due to the lifestyle provided by urology as a specialty, or a matter of selection and adaptation in the "pursuit of happiness". Hopefully this study will ignite interest in comparing satisfaction in a cohort of newly certified urologists, both male and female.

\section{REFERENCES}

1. Frank E, McMurray JE, Linzer M, Elon L: Career satisfaction of US women physicians: results from the Women Physicians' Health Study. Society of General Internal Medicine Career Satisfaction Study Group. Arch Intern Med. 1999; 159: 1417-26.

2. Zutshi M, Hammel J, Hull T: Colorectal surgeons: gender differences in perceptions of a career. J Gastrointest Surg. 2010; 14: 830-43.

3. Lerner LB, Stolzmann KL, Gulla VD: Birth trends and pregnancy complications among women urologists. J Am Coll Surg. 2009; 208: 293-7.

4. Lerner LB, Baltrushes RJ, Stolzmann KL, Garshick E: Satisfaction of women urologists with maternity leave and childbirth timing. J Urol. 2010; 183: 2826. 
5. Marley CS, Lerner LB, Panagopoulos G, Kavaler E: Personal, professional and financial satisfaction among American women urologists. Int Braz J Urol. (in press)

\author{
Dr. Sarah Ramsey \\ Department of Urology \\ Gartnavel General Hospital \\ Glasgow, United Kingdom \\ E-mail: sara_l_ramsey@ntlworld.com
}

